\title{
SIKLUS HIDUP PERUSAHAAN DAN KONSERVATISME AKUNTANSI
}

\author{
Nur Wachidah Yulianti \\ UIN Syarif Hidayatullah Jakarta
}

\begin{abstract}
This research analyzes influence of corporate life cycle to accounting conservatism. Corporate life cycle consists of start up, growth, mature and decline phase. This research used 90 sample corporates from secondary sector at Indonesia Stock Exchange (IDX) in 2011. The result of this research shows that corporates sample on mature phase did accounting conservatism in order to stay on that phase and never fell down on decline phase. But, corporate samples on growth phase didn't do accounting conservatism because they needed more financing. This research expected to give an empirical evidence about influence corporate life cycle to accounting conservatism.
\end{abstract}

Keywords : corporate life cycle, accounting conservatism, growth phase, mature phase

\section{PENDAHULUAN}

Sama halnya seperti manusia, setiap perusahaan juga memiliki tahapan siklus hidup dari mulai lahir (startup), tumbuh dan berkembang (growth), dewasa (mature) sampai tiada (decline) dan bagi perusahaan pada tiap tahapan siklus hidup yang dijalaninya memiliki karakteristik ekonomi yang berbeda (Black, 1998). Karakteristik ekonomi tersebut pada akhirnya akan berdampak pada kebijakan akuntansi yang diambil manajemen (Yang \& Li, 2009).

Yonpae (2006) menyatakan bahwa tahapan siklus hidup perusahaan telah banyak digunakan oleh analis keuangan dan peneliti untuk menggambarkan atribut ekonomi dari suatu perusahaan. Literatur tentang siklus hidup perusahaan menunjukkan bahwa (1) tahapan siklus hidup perusahaan dapat menjelaskan perbedaan di bidang ekonomi yang mendasari nilai-relevan suatu atribut seperti fungsi produksi dan set kesempatan investasi, (2) perusahaan di berbagai tahapan siklus hidup perlu mengelola bisnis yang berbeda untuk dapat menjadi sukses, dan (3) kesadaran khusus mengenai tahapan siklus hidup perusahaan dapat menambah pemahaman mengenai pada posisi mana perusahaan berada dan dimana perusahaan harus berjalan.

Prinsip akuntansi yang berlaku umum (Generally Accepted Accounting Principles) memberikan fleksibilitas bagi manajemen dalam menentukan metode maupun estimasi akuntansi yang dapat digunakan. Fleksibilitas tersebut akan mempengaruhi perilaku manajer dalam melakukan pencatatan akuntansi dan pelaporan transaksi keuangan perusahaan. Dalam kondisi keragu-raguan, seorang manajer harus menerapkan prinsip akuntansi yang bersifat konservatis (Wardhani, 2008). Konservatisme akuntansi dapat menetralisir optimisme para usahawan yang terlalu berlebihan dalam melaporkan hasil usahanya (Sari, 2009). 
Konservatisme telah menjadi prinsip akuntansi yang banyak dianut oleh para akuntan sejak abad ke-15 dan semakin popular penggunaannya dalam tiga dekade terakhir. FASB Statement of Concept No. 2 mendefinisikan konservatisme sebagai reaksi hati-hati (prudent reaction) menghadapi ketidakpastian. Hal ini dilakukan untuk memastikan bahwa ketidakpastian dan resiko yang melekat pada situasi bisnis telah cukup dipertimbangkan (Haniati, 2010)

Sejauh pengetahuan penulis, hanya ada sedikit penelitian yang mencoba menguji secara langsung pengaruh tahapan siklus hidup perusahaan dengan konservatisme akuntansi yaitu Kung H Chen dan Yonpae Park (2006) dengan papemya yang berjudul "Accounting Conservatism and Firm Life-Cycle Stages" dan Willow Yang-Liu Li (2009) dengan papernya yang berjudul "Accounting conservatism and the impact of the firm's life cycle", namun sayangnya penulis tidak berhasil mendapatkan paper atas penelitian tersebut. Dengan menggunakan sampel perusahaan yang berada dalam sektor sekunder Bursa Efek Indonesia pada tahun 2011, penelitian ini bertujuan untuk menguji apakah tahapan siklus hidup perusahaan berpengaruh terhadap konservatisme akuntansi perusahaan. Penelitian ini diharapkan memberikan manfaat bagi pengembangan ilmu pengetahuan dan praktisi. Bagi pengembangan ilmu pengetahuan, penelitian ini diharapkan dapat memberikan bukti empiris mengenai bagaimana pengaruh tahapan siklus hidup perusahaan terhadap praktek konservatisme akuntansi di Indonesia. Sedangkan bagi praktisi, penelitian ini diharapkan dapat memberikan informasi mengenai tahapan siklus hidup perusahaan dan bagaimana pengaruhnya terhadap tingkat konservatisme yang diterapkan oleh perusahaan.

\section{METODOLOGI PENELITIAN}

\section{Data dan Sampel}

Penelitian ini menggunakan data sekunder sebagai bahan penelitian yaitu Laporan Keuangan perusahaan dalam industri sekunder yang terdaftar di Bursa Efek Indonesia (BEI) periode 2011. Adapun metode dalam pemilihan sampel penelitian menggunakan metode purposive sampling, dimana sampel dipilih berdasarkan pada kriteria di bawah ini:

a) Perusahaan yang terdaftar di BEI dan mempublikasikan Laporan Keuangan Auditan per 31 Desember 2011 secara konsisten dan lengkap.

b) Perusahaan sampel harus memiliki komponen yang diperlukan sebagai variabel penelitian secara lengkap

c) Laporan Keuangan menggunakan mata uang Rupiah.

\section{Pengukuran Variabel dan Model Penelitian}

Untuk menjawab hipotesis penelitian pengukuran accounting conservatism sebagai variabel dependen merujuk pada Ahmed (2007) yang diukur melalui: 
Total Accrual $=$ net income before extraordinary item - operating cashflow + depreciation expense

Sebagai variabel independen adalah tahapan siklus hidup perusahaan yang diukur bedasarkan percent sales growth dengan rumus sebagai berikut:

$\mathrm{SGt}=\left(\right.$ Sales $_{\mathrm{t}}-$ Sales $\left._{\mathrm{t}-1}\right) /$ Sales $_{\mathrm{t}-1} \times 100$

a. Apabila perusahaan sampel memiliki nilai $\mathrm{SG}_{\mathrm{t}}$ diatas $20 \%$ maka akan dikelompokan dalam tahap growth

b. Apabila perusahaan sampel memiliki nilai $S_{\text {t }}$ antara $8 \%$ sampai $20 \%$ maka akan dikelompokan dalam tahap mature

c. Apabila perusahaan sampel memiliki nilai $\mathrm{SG}_{\mathrm{t}}$ dibawah $8 \%$ maka akan dikelompokan dalam tahap decline

Tahap siklus hidup perusahaan menjadi dummy variable. Karena terdapat 3 tahap hidup perusahaan yang akan diuji, maka ada dua tahap siklus hidup perusahaan yang akan menjadi dummy variable yaitu growth dan mature dan decline sebagai variabel referensi. Sebagai variabel kontrol digunakan variabel ukuran perusahaan, leverage dan Profitabilitas. Menurut Watts dan Zimmerman (1978), ukuran perusahaan (SIZE) akan mempengaruhi tingkat biaya politis yang dihadapi perusahaan sehingga akan mempengaruhi penggunaan prinsip akuntansi yang konservatis (Wardhani, 2008). Semakin besar rasio leverage (LEV), semakin besar pula kemungkinan perusahaan akan menggunakan prosedur yang meningkatkan laba periode sekarang atau laporan keuangan disajikan cenderung tidak konservatif (optimis) (Sari, 2009), namun menurut Wardhani (2008), semakin tinggi tingkat leverage maka semakin besar kemungkinan konflik yang akan muncul antara shareholders dan bondholders yang pada akhirnya akan mempengaruhi permintaan kontraktual terhadap akuntansi yang konservatis. Menurut Ahmed et al., (2002) dalam Wardhani (2008) Perusahaan dengan profitabilitas (PROFIT) yang tinggi cenderung untuk lebih menggunakan prinsip akuntansi konservatis. Dengan demikian, untuk menguji hipotesis ini, maka model yang digunakan adalah:

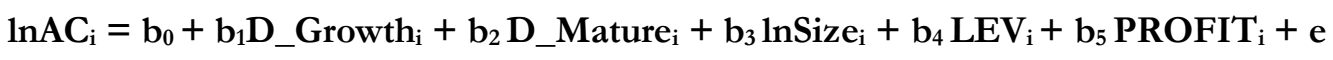

Dimana

$\ln \mathrm{AC}=$ logaritma natural dari Accounting Conservatism perusahaan $\mathrm{i}$

D_Growth $=$ dummy perusahaan perusahaan i tahap growth. Bernilai 1 jika growth, 0 lainnya

D_Mature = perusahaan perusahaan $\mathrm{i}$ tahap mature. Bernilai 1 jika mature, 0 lainnya

$\operatorname{lnSIZE} \quad=\ln$ total asset pada perusahaan $\mathrm{i}$

$\mathrm{LEV}=$ total long term liabilities per total aset perusahaan $\mathrm{i}$

PROFIT = Return On Asset (ROA) laba bersih dibagi dengan total aset perusahaan $\mathrm{i}$ 
Ekspektasi dari model di atas adalah $\mathrm{b} 1>0$, b2 $>0$, b3 $>0$, b4 $<0$ dan b5 $>0$

Operasionalisasi variabel yang digunakan dalam model di atas dapat dilihat dalam Tabel 1.

\section{Pengujian Model}

Model di atas akan diestimasi dengan menggunakan regresi OLS dengan cross sectional data melalui program SPSS ver 19. Dalam pengujian ini juga akan diuji terpenuhinya asumsi BLUE (Best Linear Unbiased Estimate) dimana model tersebut harus memenuhi asumsi terdistribusi dengan normal, tidak ada heteroskedastisitas, tidak terjadi multicollinearity, dan tidak terjadi autokorelasi (Wardhani, 2008).

\section{ANALISIS DAN PEMBAHASAN}

Penelitian ini mengambil sampel perusahaan yang termasuk dalam sektor sekunder di BEI pada tahun 2011. Total sampel yang memenuhi kriteria purposive sampling dalam penelitian ini sebanyak 90 perusahaan. Berdasarkan pengolahan data, dapat dilihat bahwa 0,41 (41\%) sampel merupakan perusahaan yang berada pada fase growth. Hal ini berarti bahwa rata-rata sebanyak $41 \%$ perusahaan memiliki tingkat percent sales growth sebesar $20 \%$ ke atas. Sedangkan 37\% sampel merupakan perusahaan pada mature untuk perusahaan dengan fase mature. Ini berarti bahwa rata-rata sebanyak 37\% perusahaan memiliki percent sales growth sebesar $8 \%$ sampai $20 \%$.

\section{Analisis pengaruh tahapan siklus hidup perusahaan terhadap konservatisme akuntansi. \\ Untuk menguji dan menganalisis pengaruh tahapan siklus hidup perusahaan terhadap accounting conservatism perusahaan di Indonesia, maka dilakukan pengujian dengan menggunakan persamaan regresi yang telah dijelaskan dalam model.}

\section{Pengujian Hipotesis}

Berdasarkan tabel 2 dapat dilihat bahwa angka adjusted $\mathrm{R}$ square sebesar 0,220. Hal ini berarti bahwa $22 \%$ dari accounting conservatism dapat dijelaskan oleh variabel independen yang ada dalam model dan sisanya dijelaskan oleh variabel lain. Hasil pengujian $F$ test menunjukkan bahwa secara keseluruhan, semua variabel independen dalam model berpengaruh signifikan terhadap accounting conservatism.

Berdasarkan uji t untuk tiap-tiap variabel independen, variabel D_Mature dan variabel kontrol: lnSIZE, LEV dan Profit signifikan pada level 5\%, sedangkan variabel D_Growth tidak signifikan pada level 5\%. Penelitian ini tidak dapat membuktikan bahwa perusahaan pada fase growth berpengaruh terhadap accounting conservatism atau dengan kata lain, penelitian ini tidak dapat membuktikan bahwa perusahaan pada fase growth cenderung untuk melakukan accounting conservatism. Menurut Juniarti (2005), Perusahaan pada fase growth yaitu dengan kriteria sales growth lebih dari 20\%, masih melakukan pengeluaran investasi yang 
sangat besar untuk mengembangkan dan mempertahankan pangsa pasar serta menguasai teknologi. Sehingga memerlukan financing activity yang lebih besar. Kebutuhan akan pendanaan yang besar, membuat perusahaan pada fase growth tidak konservatif (agresif). Dengan demikian hasil ini menolak hipotesis bahwa perusahaan pada fase growth cenderung melakukan accounting conservatism.

Variabel D_Mature signifikan positif dengan nilai koefisien sebesar 0,868 dan $p$ value sebesar 0,037. Hasil ini menunjukan bahwa perusahaan pada fase mature cenderung untuk melakukan accounting conservatism. Perusahaan pada fase mature cenderung untuk bersikap konservatif didorong oleh motif untuk mempertahankan posisi 'mature' dan tetap menguasai pangsa pasar. Hasil ini mendukung hipotesis bahwa perusahaan pada fase mature cenderung untuk melakukan accounting conservatism. Variabel kontrol ukuran perusahaan (lnSIZE), leverage (LEV) dan profitabilitas (Profit) memiliki signifikasi positif yang sesuai dengan prediksi. Hasil ini menunjukkan bahwa semakin besar ukuran perusahaan dan profitabilitas perusahaan maka akan cenderung melakukan accounting conservatism dan semakin tinggi leverage perusahaan maka semakin cenderung untuk melakukan accounting conservatism.

Uji normalitas membuktikan bahwa hasil penelitian ini telah terdistribusi normal. Uji terhadap adanya autokorelasi melalui Durbin Watson $(D W)$ test menunjukkan hasil bahwa DW bernilai 2,052. Menurut Gujarati (2006) Nilai DW sebesar 2,052 dibandingkan dengan nilai tabel dengan menggunakan derajat kepercayaan 5\%, jumlah sampel 90 dan jumlah variabel bebas 4, maka di tabel Durbin Watson akan didapatkan nilai batas bawah (dL) 1,566 dan batas atas (dU) 1,751. Oleh karena nilai DW 2,052 lebih besar daripada batas atas (du) 1,751 maka dapat disimpulkan tidak terdapat autokorelasi positif pada model regresi. Nilai VIF untuk setiap variabel tidak melebihi 10, sehingga dapat dikatakan hasil penelitian ini tidak mengindikasikan gejala multikolinearitas. Hasil pengujian ini dapat dilihat dalam lampiran. Berdasarkan pengujian diatas, dapat dikatakan penelitian in telah memenuhi kaidah BLUE (Best Linear Unbiased Estimate).

\section{KESIMPULAN}

Penelitian ini bertujuan untuk menguji pengaruh tahapan siklus hidup perusahaan terhadap praktik accounting conservatism. Tahapan siklus hidup perusahaan yang terdiri dari startup, growth, mature dan decline dihubungkan dengan tingkat konservatisme akuntansi yang diukur melalui total akrual. Hasil penelitian menunjukkan bahwa perusahaan pada fase mature cenderung untuk melakukan accounting conservatism dengan tujuan agar dapat tetap berada pada posisi 'mature' dan tidak jatuh dalam posisi decline serta tetap menguasai pangsa pasar. Berbeda hasil dengan perusahaan pada fase mature, perusahaan pada fase growth justru tidak melakukan accounting conservatism, hal ini karena, perusahaan pada fase growth memiliki financing 
activity yang lebih besar. Kebutuhan akan pendanaan yang besar, membuat perusahaan pada fase growth tidak konservatif (agresif).

Penelitian ini memiliki banyak kekurangan, diantaranya pertama, sampel dalam penelitian ini terlalu sedikit dan hanya meliputi perusahaan dalam industri sekunder, sehingga hasil penelitian ini tidak dapat digenaralisasi untuk industri lain. Kedua, pengukuran tahapan siklus hidup hanya berdasarkan pada satu indikator saja yaitu percent sales growth, sehingga hasil penelitian yang menunjukkan bahwa perusahaan dengan fase growth cenderung tidak konservatif dan fase mature cenderung konservatif, belum tentu sama jika menggunakan indikator tahapan siklus hidup perusahaan yang lain. Dan yang terakhir, penelitian ini hanya menggunakan proxy total akrual saja dalam menentukan konservatisme suatu perusahaan, masih banyak proxy konservatisme akuntansi lainnya yang dapat digunakan untuk menentukan konservatisme suatu perusahaan agar hasil penelitian ini dapat diperbandingkan.

\section{REFERENSI}

Anwer S. Ahmed, S. D. (2007). Accounting conservatism and board of director. Journal of Accounting and Economics , 411-437.

Beaver, W. H. (2005). Conditional and Unconditional Conservatism: Concepts and Modeling. Review of Accounting Studies 10, Springer Science+Business Media, Inc. , 269-309.

Biddle, G. C. (2012). Accounting Conservatism and Bankrupty Risk. Social Science Research Network.

Black. (1998). Life-Cycle Impacts on the Incremental V alue-Relevance of Earnings and Cash Flow Measures. The Journal of Financial Statement Analysis , 40-56.

Firdaus. (2009). Pengaruh Tahapan Siklus Hidup Perusahaan Terbadap Pembayaran Pajak Penghasilan Perusahaan. Depok: Fakultas Ekonomi Departemen Akuntansi.

Gujarati, D. (2006). Essentials of Econometrics. McGraw-Hill International Edition.

Haniati, S. (2010). Pengaruh Konservatisme Terbadap Asimetri Informasi dengan Menggunakan beberapa model pengukuran Konservatisme. Simposium Nasional Akuntansi. Purwokerto: Ikatan Akuntan Indonesia.

Heltzer, W. (2009). Conservatism and Book-Tax Differences. Journal of Accounting, Auditing \& Finance, 469-504.

Higgins, R. C. (2007). Analysis For Financial Management. New York: McGraw-Hill Irwin.

Juniarti. (2005). Mana yang lebih memiliki value relevant: Net Income atau Cash Flow (Studi Terbadap Siklus Hidup Organisasi). Jurnal Akuntansi dan Keuangan Vol. 7, Jurusan Ekonomi Akuntansi, Fakultas Ekonomi - Universitas Kristen Petra , 22-42.

Lara, J. M. (2007). Accounting conservatism and corporate governance. Springer Science+Business Media , 161-201. 
Qiang, X. (2007). The Effects of Contracting, Litigation, Regulation, and Tax Cost on Conditional and Unconditional Conservatism: Cross Sectional Evidence at the Firm Level. The Accounting Review , 759-796.

Razzaq, N. (2007). BAB III METODOLOGI PENELITLAN. Dipetik Desember 12, 2012, dari www.lontar.ui.ac.id/file?file $=$ digital $/ 126316-5682 \ldots . p d f$

Sari, C. (2009). Konservatisme Perusahaan di Indonesia dan faktor-faktor yang mempengarubinya. Simposium Nasional Akuntansi XII. Palembang: Ikatan Akuntan Indonesia.

Susanto, S. (2006). Relevansi Nilai Informasi Laba dan Aliran Kas Terhadap Harga Sabam dalam Kaitannya dengan Siklus Hidup Perusahaan. Simposium Nasional Akuntansi IX. Padang: Ikatan Akuntan Indonesia.

Wardhani, R. (2008).Tingkeat Konservatisme Akuntansi di Indonesia dan Hubungannya dengan Karakteristik. Dewan sebagai salah satu mekanisme Corporate Governance. Simposium Nasional Akuntansi XI. Ikatan Akuntan Indonesia.

Watts, R. L. (2003). Conservatism in Accounting Part I. Accounting Horizon, 207-221.

Yang, W., \& Li, L. (2009, May 29). Dipetik Desember 11, 2012, dari http://www.business.auckland.ac.nz/uoa/home/for/current students/graduation/student-events/events/template/event_item.jsp?cid=360694

Yonpae, P. (2006). The Effect Of Accounting Conservatism And Life-Cycle Stages On Firm Valuation. Journal of Applied Business Research 